\title{
A HIERARQUIA DOS TRATADOS INTERNACIONAIS NO ORDENAMENTO INTERNO FRANCÊS ${ }^{1}$
}

\author{
THE HIERARCHY OF INTERNATIONAL TREATIES IN FRENCH INTERNAL LAW SYSTEM
}

Charles-Henry Chenut ${ }^{2}$

Bom dia a todos. É um grande prazer para mim estar aqui hoje com vocês nessa Universidade de tanto prestígio. Eu gostaria de agradecer, em especial, o meu amigo, Paulo Casella, por me dar essa oportunidade de compartilhar com vocês um pouco do Direito francês e do Direito europeu: terras distantes onde se aventuram cada vez mais empresas e investidores brasileiros.

O tema que eu gostaria de abordar hoje faz parte da matéria de Direito Público, mais especificamente sobre a hierarquia de normas internacionais num ordenamento interno. O meu tema então é o seguinte: A hierarquia dos tratados internacionais no ordenamento interno francês. A apresentação da realidade francesa, sobre essa matéria, objetiva despertar a reflexão de vocês em relação ao Sistema brasileiro existente.

Eu me proponho então a abordar, em primeiro lugar, a regra de princípio que define a ordem hierárquica das normas na França; num segundo momento, estudaremos as diferentes aplicações práticas dessas regras, abordando de maneira distinta a integração do Direito comunitário e depois a integração do Direito europeu no ordenamento jurídico francês.

Comecemos primeiro com o princípio que rege a hierarquia de normas na França.

\section{O Princípio: A Ordem Hierárquica das Normas}

Uma introdução histórica sobre o assunto me parece interessante. Isso porque a hierarquia de normas tradicional, estabelecida na França, desde o século XVII, foi sucedida por uma nova hierarquia de normas a partir dos anos 60 devido à internacionalização do Direito.

Vamos estudar primeiramente a hierarquia tradicional de normas na França.

\footnotetext{
Conferência proferida em 26 de setembro de 2007.

2 Doutor em Direito. Advogado sócio - rawlings Giles LLP (Paris). Professor de Direito no Institut d'Études Politiques de Paris (Sciences Po.). Conselheiro do Comércio Exterior da França e Secretário Geral da Commissão América Latina (CNCCEF).
} 
A - A hierarquia tradicional de normas na França

- As razões do Direito nacional

O postulado de base é o seguinte: os atos que emanam de uma autoridade habilitada (do Parlamento ou do Governo - Poder Executivo, por exemplo) não têm o mesmo valor juridicamente. Eles não possuem a mesma força, eles se posicionam de maneira diferente uns em relação aos outros.

Historicamente, desde o século XVII, as normas de Direito eram hierarquizadas em função dos poderes detidos pelo orgão que as emitia - e não do seu conteúdo.

Foi entre o final do século XVIII e o começo do século XIX que uma hierarquia de normas nasceu oficialmente, sendo finalmente conceitualizada e descrita em detalhes por Kelsen. Segundo esse Autor, pai da Escola de Viena, o Direito é uma Ciência composta por normas organizadas sob a forma de uma pirâmide.

- A pirâmide de normas (Kelsen)

No topo da pirâmide está a constituição, norma suprema, universal, texto fundamental da nação; ato sagrado (às vezes existe o religioso no jurídico), norma cuja intangibilidade garante a estabilidade de um país e a perenidade de sua organização. Depois, abaixo da Constituição, se situa a lei que emana do Poder Legislativo (do Parlamento). A lei tira a sua legitimidade de seu caráter geral; ela é votada por todos e é destinada a todos. Por fim, abaixo da lei, está o regulamento que emana do Poder Executivo (o Governo). A destinação particular dessa norma coloca-a num nível logicamente inferior à lei e, $a$ fortiori, inferior à constituição.

Essa hierarquia de normas possuía uma certa lógica imbatível até o momento em que o Direito Internacional veio fissurar o edifício perfeitamente descrito por Kelsen.

Uma nova hierarquia de normas então apareceu, sucedendo a primeira, ocasionada pela proliferação de tratados internacionais. É sobre esse segundo ponto que eu gostaria agora de tratar. 
B-A nova hierarquia de normas na França

- A influência do Direito Internacional

A partir do século XIX, um aumento - às vezes frenético mas de qualquer forma caótico - dos tratados internacionais veio desafiar a ordem normativa estabelecida até o momento. Assim, o Direito Internacional se impôs, às vezes sem autorização, forçando os direitos nacionais a levá-lo em consideração. O Direito Internacional veio bagunçar os direitos nacionais, às vezes com desprezo ou mesmo com desdém!

A Constituição francesa, de 1958, concebida pelo general De Gaulle, veio apitar o final do jogo para tentar colocar um pouco de ordem na luta então travada entre normas nacionais e internacionais, cada uma reivindicando sua supremacia e sua autoridade.

- A Constitução francesa (1958)

De forma muito clara, a Constituição francesa criou assim dois princípios:

- O primeiro princípio é o da primazia da Constituição sobre o tratado internacional. Os arts. 53 e 54 da Constituição dispõem, de fato, que os tratados internacionais são inferiores à Constituição.

Conseqüentemente, uma disposição de um tratado internacional contrária a uma disposição da Constituição francesa não poderia ser invocada na França. Essa primazia da Constituição foi firmemente sustentada por uma decisão do Tribunal Constitucional francês, em 2 de setembro de 1992. Portanto, salvo modificação da Constituição francesa, o tratado internacional «contrário» não se aplica.

Por que uma tal situação? Simplesmente porque a soberania nacional pertence somente ao povo e a seus representantes - representantes que adotaram a Constituição - e porque essa soberania nacional não pode legitimamente ser transferida a uma organização internacional ou a uma comunidade de países - que tenham adotado um tratado.

- O segundo princípio editado pela Constituição francesa é o da primazia do tratado internacional sobre a lei nacional. O tratado internacional não é pois totalmente excluído da hierarquia de normas francesas. O art. 55 da Constituição francesa precisa que o tratado internacional é superior à lei nacional sob a condição, entretanto, que este tratado seja regularmente ratificado e aprovado pelo Parlamento francês. Respeitada essa condição, o tratado internacional entra então na ordem jurídica francesa. 
Isso significa que, quando um tratado internacional foi aprovado pelo Parlamento francês, esse tratado se impõe como qualquer disposição adotada legitimamente pelo Parlamento, expressão da vontade popular. A lei nacional contrária não é mais invocável. Ela é abrogada; são as disposições do tratado que prevalecem.

Essa idéia não é difícil de entender quando um tratado entra em conflito com uma lei nacional, adotada antes do tratado. Pois o tratado internacional - desde que tenha sido adotado pelo Parlamento - é considerado como um novo ato legislativo e abroga assim a lei anterior contrária.

Esse princípio da primazia do tratado sobre a lei nacional é mais difícil de entender quando o tratado entra em contradição com uma lei adotada depois do tratado. Aqui não é mais o caráter horizontal do tempo que está em jogo - a lei posterior contrária não prima sobre o tratado anterior. O que importa aqui, é o caráter vertical da hierarquia de normas. Um tratado continua sempre superior a uma lei contrária, mesmo se esta for posterior. Tanto o tratado como a lei são normas adotadas pelo Parlamento, mas o tratado continua sendo um ato mais importante - devido à sua natureza internacional - que a lei - a qual possui apenas uma natureza nacional.

Em conseqüência, a nova hierarquia de normas na França é hoje a seguinte (partindo da norma mais importante para a norma menos importante): a constituição, depois o tratado internacional, depois a lei, depois o regulamento.

Após ter explicado as regras de princípio, eu proponho que observemos agora, como na prática o Direito Internacional é aplicado na ordem interna. A resignação de uns é, às vezes, sucedida pela rebelião de outros.

\section{As Aplicações: Entre Resignação e Rebelião}

Antes, a resignação. Trata-se de uma integração, sem falhas, do Direito comunitário na ordem interna. Uma regra. Algumas relativizações.

A - Integração do Direito comunitário na ordem interna: a resignação

- A regra: a superioridade do Direito comunitário na ordem interna

O Direito comunitário - diferentemente do Direito europeu, sobre o qual falaremos daqui a pouco, é composto pelo conjunto de normas da União Européia.

Trata-se, por um lado, do Direito comunitário originário (Tratado de Roma de 1957, ato único de 1986, depois os tratados de Maastrich, de 1992, de Amsterdam, 
de 1997, e de Nice, de 2001). Para esse Direito comunitário originário, nunca houve dificuldade de integração pois, segundo o texto da Constituição francesa, o tratado internacional é inferior à Constituição mas superior à lei nacional.

Em contrapartida, questões surgem a respeito do Direito comunitário, não do originário, mas do Direito comunitário derivado. Não se trata aqui dos textos fundadores da União Européia, mas de normas regularmente editadas pelos órgãos da União. Existem três categorias principais de atos derivados: o regulamento, a diretiva e a decisão.

- O regulamento, em primeiro lugar. É uma norma de alcance geral que se dirige a uma categoria inteira de pessoas (por exemplo, os pescadores, os produtores de etanol, os estabecimentos de venda de tabaco). O regulamento possui um efeito direto em cada Estado da União Européia. Isso significa que o cidadão francês pode invocar uma disposição do regulamento europeu perante as jurisdições francesas, mesmo que o regulamento não tenha sido previamente adotado pelo Parlamento francês. A transposição do regulamento na ordem interna nacional não é obrigatória.

Por quê? Porque um Estado europeu não pode interferir na interpretação do regulamento quando da sua transposição na ordem interna. Há uma vontade de aplicar o regulamento, diretamente, de forma similar em todos os Estados, simultaneamente e de maneira uniforme em toda a comunidade européia.

- Segunda norma derivada do Direito comunitário: a diretiva. A situação aqui é inversa. A diretiva é uma norma de alcance mais restrito que o regulamento. A diretiva fixa objetivos a serem atingidos pelos Estados membros, mas ela não impõe condições para atingir tais objetivos.

Em outras palavras, o Estado francês deve aplicar a diretiva, mas ele fica livre para definir os meios necessarios para realizar o que lhe foi demandado. A diretiva não possui, portanto, um efeito direto na ordem interna francesa. É preciso esperar um ato de transposição desta norma comunitária - ato de transposição do Parlamento francês - para que um cidadão possa validamente invocar o ato transposto diante de uma jurisdição nacional.

- Terceira e última norma derivada: a decisão. É uma disposição que emana geralmente da comissão européia e que visa indivíduos em particular (como a empresa, o sindicato). A decisão tem um caráter obrigatório quanto ao objetivo a ser atingido - como a diretiva -, mas a disposição possui também um caráter obrigatório em relação aos meios empregados para atingir esse objetivo - diferentemente da diretiva.

Não há escolha nesse caso. Trata-se de uma norma obrigatória que não cria direitos particulares, mas que impõe uma conformidade da legislação nacional ao Direito comunitário. O efeito da decisão é direto. 
Em conseqüência, constata-se que o Direito comunitário - original ou derivado - integra-se perfeitamente - diretamente ou indiretamente - na hierarquia de normas francesas. Entretanto, em relação a essa regra, à qual todos parecem se resignar, existem algumas relativizações.

Tais relativizações conferem à integração do Direito comunitário um caráter relativo, e não mais realmente absoluto como se poderia imaginar.

- As relativizações: a relatividade do Direito comunitário na ordem jurídica francesa

- Primeira relativização : a questão prejudicial em interpretação (relatividade temporal)

Todo cidadão de um Estado membro pode apresentar uma questão prejudicial diante do seu juiz nacional, a fim de pedir que a norma comunitária, que lhe é imposta, seja corretamente interpretada. Esse direito de oposição é previsto no art. 234 do tratado da Comunidade Européia. Quando o cidadão faz uso desse direito, o juiz nacional é obrigado a suspender o processo, a enviar a questão à Corte de Justiça das comunidades européias e a esperar a resposta desta Corte.

A idéia é a de tornar uniforme o Direito comunitário, que não deve ser aplicado de forma diferente nos diversos Estados. A natureza direta e imediata das normas comunitárias perde assim sua força e adquire uma relatividade temporal.

- Segunda relativização: o controle judicial para a anulação (relatividade universal)

Previsto no art. 230 do tratado das comunidades européias, o recurso de anulação é aberto a todo cidadão de um Estado-membro que solicitar à Corte de Justiça das comunidades européias a anulação de uma norma comunitária (regulamento, diretiva ou decisão).

Esse recurso permite a anulação do ato se seu caráter ilegal é reconhecido. É preciso que ele seja contrário às disposições do tratado da União Européia. A relatividade do Direito comunitário não é mais temporal nesse caso - não se suspende a aplicação da norma comunitária durante a interpretação pela Corte de Justiça; aqui a relatividade do Direito comunitário torna-se universal - pois a anulação da norma é definitiva e invocável por todos e não-somente por aquele que pediu a anulação do ato. 
Eis a aplicação do Direito comunitário no ordenamento interno francês: uma integração resignada do direito comunitário no ordenamento francês temperada por relativizações.

Quanto ao Direito europeu, sua integração é mais complexa. Ela suscitou mais contestações.

B - Integração do Direito europeu na ordem interna: a rebelião

Se o Direito comunitário - que acabamos de estudar - abrange os tratados da União Européia, o Direito europeu trata da aplicação da Convenção Européia dos Direitos do Homem, assinada em 4 de novembro de 1950, e ratificada pela França, em 1974.

Esta Convenção faz parte da ordem jurídica internacional. Para controlar a aplicação da Convenção, uma Corte especial foi criada: a Corte Européia de Direitos Humanos.

O problema da incorporação da Convenção Européia de Direitos Humanos na ordem interna francesa é, portanto, o mesmo da incorporação de qualquer tratado internacional. Mas a dúvida que rapidamente surgiu foi sobre a possibilidade de um cidadão francês invocar essa Convenção e seus direitos - direito ao respeito da vida privada, direito ao respeito da propriedade, por exemplo - diretamente diante dos tribunais franceses ou apenas a posteriori diante da Corte Européia de Direitos Humanos.

A dúvida é se a Convenção Européia de Direitos Humanos é uma fonte de direito autônoma, imediata e diretamente aplicável na França, ou se esta Convenção é um direito derivado que não faz parte da paisagem jurídica francesa, unicamente destinada a ser invocada diante da Corte Européia de Direitos Humanos, jurisdição independente e supranacional.

A resposta a essa questão possui evidentemente um interesse prático para o particular, pois a Convenção Européia de Direitos Humanos prevê que a Corte não pode ser acionada, a não ser que as vias de recurso nacionais tenham sido totalmente esgotadas.

Em outros termos, é preciso esperar o fim da ação judicial na França (ação que pode ir até a Corte suprema e durar anos) para invocar, pela primeira vez, uma violação da Convenção Européia dos Direitos Humanos, diante da própria Corte, ou podese invocar essa violação imediatamente perante as jurisdições francesas, desde o primeiro grau de jurisdição, sem esperar para acionar a Corte Européia de Direitos Humanos. Essa 
última solução permitiria uma melhor proteção dos direitos de cada cidadão, através de uma defesa mais rápida e menos custosa assegurada pelo juiz nacional.

A aplicação direta na França da Convenção suscitou grandes controvérsias de princípio. Essa rebelião da doutrina - contra uma aplicação direta da Convenção influenciou bastante, na prática, os operadores do Direito (juízes e advogados), que hoje - em dia - acabaram por aplicar a Convenção, mas com uma certa reserva; reserva que não se justifica juridicamente.

Eu gostaria de explorar melhor esses dois aspectos.

- Aplicação controvertida da Convenção Européia na teoria: os protestos da doutrina

A aplicação direta da Convenção Européia, diante das jurisdições francesas, alimentou um vivo debate ainda que, devido à sua natureza de tratado internacional e a partir de sua ratificação pela França, poder-se-ia crer que a Convenção Européia teria sido integrada sem grandes dificuldades na hierarquia de normas francesa, como todo tratado internacional.

Ora, o espírito de contradição - tipicamente francês - curiosamente tomou conta do problema, contrariamente às expectativas.

- Os argumentos contrários a uma aplicação direta da Convenção foram os seguintes:

Primeiro argumento: uma aplicação direta é contrária ao espírito da Convenção. Esse texto protege direitos de ordem pública, invocáveis por um particular contra seu Estado. A Convenção não trata de direitos de ordem privada invocáveis entre particulares. Se esse fosse o caso, o espírito do texto não estaria sendo respeitado.

Segundo argumento: uma aplicação direta da Convenção é contrária à vocação da Convenção. Esse texto é destinado a proteger um particular contra seu Estado que violou a Convenção. A Convenção não protege um particular contra um outro particular. O litígio puramente privado não faz parte do objeto da Convenção.

Terceiro argumento: a aplicação direta é contrária à coerência da Convenção. Esse texto é destinado a ser interpretado por um único órgão criado para isso: a Corte Européia de Direitos Humanos. Ao se permitir que um juiz nacional aplique a Convenção, permitem-se interpretações diversas desse texto. A Corte Européia perderia o controle de uma aplicação uniforme. Uma desigualdade de tratamento entre cidadãos europeus poderia surgir. 
- A tais argumentos desfavoráveis à aplicação direta, uma parte da doutrina respondeu que a Convenção é um tratado internacional como qualquer outro e que convém aplicar as regras de Direito Internacional Público. Assim, se um tratado é auto-executável (ou seja, não necessita de medidas internas prévias de regulamentação) e se o tratado protege interesses privados (ou seja, não trata apenas de interesses inter-estatais), então esse tratado é diretamente aplicável na ordem interna.

Ora, a Convenção Européia cumpre com essas duas condições. É a razão pela qual a Corte européia reconheceu o princípio de aplicação direta da convenção por um juiz nacional num litígio puramente privado. Sentença proferida em 18 de janeiro de 1978.

O juiz francês foi, a partir daí, incitado a aplicar diretamente a Convenção européia. Mas os protestos da doutrina marcaram os espíritos dos operadores franceses. Na prática, a aplicação direta da Convenção continua restrita e insubordinada.

- A aplicação restrita da Convenção Européia na prática: a insubordinação dos profissionais

Após algumas hesitações, o juiz francês acabou por aplicar, diretamente, a Convenção Européia no Direito interno. Duas decisões da Corte de Cassação (a corte suprema francesa) marcaram esse passo: em 3 de junho de 1975 (sentença Respiro) e em 30 de junho de 1976 (sentença Touvier).

A solução encontrada nessa última decisão é particularmente clara. Eu cito: «em virtude do art. 55 da Constituição francesa, a Convenção Européia de Direitos Humanos prima sobre a nossa legislação interna. $\mathrm{O}$ art. 55 confere inclusive à Convenção uma autoridade superior à lei. Os particulares podem, portanto, invocá-la perante os tribunais franceses, que devem aplicá-la».

Solução muito clara: aplicação direta na ordem interna da Convenção Européia. Essa Convenção torna-se, portanto, uma fonte de Direito autônoma. Finalmente, a Corte suprema aplicou, sem surpresas, o Direito Internacional Público e as regras previstas na Constituição francesa.

Mas na prática, os juízes e advogados continuam insubordinados ao princípio que acaba de ser enunciado. Na verdade, o número de decisões judiciais fundadas, apenas na violação da Convenção européia, é muito pequeno (apenas 30\% das decisões proferidas). 
As razões são as seguintes. O juiz francês prefere basear a sua decisão nas normas francesas, normas que ele conhece. Pois, o juiz francês ainda domina mal o Direito europeu. É um problema de formação profissional. Se a nova geração de juízes é mais reativa ao Direito europeu, a geração antiga (ainda em atividade) ainda experimenta dificuldades com essa matéria.

Diante dessa insubordinação dos juízes mais antigos, os advogados preferem invocar a Convenção européia, sempre juntamente com uma norma francesa (a constituição, a lei ou o regulamento). Assim, se o juiz desejar, ele poderá basear sua decisão na norma francesa e não na Convenção européia. Fica a sua escolha, incitado pelo princípio de subsidiaridade. Em contrapartida, se o advogado invoca apenas a Convenção européia, o juiz terá a obrigação de julgar considerando essa convenção e a jurisprudência da Corte européia que ele conhece mal. Essa última estratégia não é muito boa e é mais arriscada.

Na prática, portanto, a Convenção européia é altamente negligenciada. Uma parte da doutrina francesa continua resistente e, ainda, há juizes que se recusam a acreditar que a França faz parte da Europa. Mas os homens mudam e as práticas também. Com certeza, daqui a algum tempo, a questão da aplicação direta da convenção européia na ordem interna não será mais um problema. Ja é quase o caso, hoje em dia.

Em conclusão, eu gostaria simplesmente de reforçar que o Direito Internacional Público modificou, radicalmente, os sistemas jurídicos nacionais na Europa e no resto do mundo. Essa caminhada inexorável, para uma internacionalização do Direito, segue naturalmente o movimento global da economia.

Assim, se os paises devem harmonizar seus sistemas jurídicos internos, a fim de incorporar novas normas internacionais (é um movimento vertical), essas novas normas internacionais devem também buscar, entre elas, uma certa harmonia (é um movimento horizontal).

Essa segunda preocupação, que é fundamental para o equilíbrio das nações - de um ponto de vista econômico e jurídico -, infelizmente não é muito levada em consideração, atualmente, e pode criar graves distorções na aplicação interna de normas internacionais que podem - às vezes - ser contraditórias e possuir objetivos conflitantes.

Kelsen sustentava: «que é preciso atenuar, e depois apagar, a linha fronteiriça que separa o direito internacional e os direitos nacionais, de maneira que o objetivo final da evolução do direito seja a unidade orgânica de uma comunidade universal e mundial». Eu acredito, sem partilhar completamente do entusiasmo dogmático de Kelsen por um 
mundo de Direito único, que uma coerência global das normas internacionais é altamente desejável, para melhorar a estabilidade dos sistemas nacionais.

Muito obrigado.

São Paulo, setembro de 2007. 